\title{
Evaluation of the Rapid Diagnostic Test OptiMAL for Diagnosis of Malaria due to Plasmodium vivax
}

\author{
Alonso Soto Tarazona ${ }^{1}$, Lely Solari Zerpa ${ }^{1}$, \\ Daniel Mendoza Requena ${ }^{2}$, Alejandro Llanos-Cuentas ${ }^{1}$ \\ and Allan Magill ${ }^{3}$
}

Cayetano Heredia University, Institute of Tropical Medecine Alexander von Humboldt ${ }^{l}$; National Health Institute, Lima, Peru'; Walter Reed Institute of Infectious Diseases $^{3}$

Objective: To determine the sensitivity and specificity of the rapid diagnostic test OptiMAL@ for diagnosis of Plasmodium vivax malaria. Material and Methods: We included all the patients who sought medical attention in the San Martin Pangoa Hospital, Junin, an area endemic for vivax malaria in Peru, between October and December 1998, who had fever during the previous 72 hours and who were older than 12 months. The gold standard for diagnosis was thick blood film microscopy. We determined the parasitemia rate for each of the positive slides. We calculated sensitivity, specificity, positive predictive value and negative predictive value of the test. Results: We included 72 patients; 39 of them were positive for $P$. vivax by microscopic examination. The sensitivity of the Optimal test was $92.3 \%$, the specificity $100 \%$, the positive predictive value $100 \%$ and the negative predictive value $91.6 \%$. The accuracy of the test was $95.8 \%$. The sensitivity of the OptiMAL @ test progressively decreased when parasitemia was lower than 1,000 parasites/ microliter. Conclusions: the OptiMAL@ test has a high sensitivity and specificity for diagnosis of $P$. vivax malaria. However, its sensitivity decreased when parasitemia levels were lower. It is a very simple technique, which makes it a good alternative for malaria diagnosis in remote places, although its elevated cost is still a problem.

Key Words: OptiMAL, malaria, Plasmodium vivax, diagnosis, dipstick.

Malaria is the most important parasitic disease in the world. During the last decades, Peru has been an endemic country for malaria due to Plasmodium vivax, accounting in the last years for $70 \%$ of the cases reported annually [1].

One of the cornerstones in the control of malaria is early diagnosis and treatment [2-4]. Even now, the gold standard for diagnosis is microscopic examination of a thick smear, a very accurate and cheap method, but which has the disadvantage that it requires an adequate framework to maintain the equipment and material and to instruct the laboratory technicians to guarantee the

Received on 14 September 2003; revised 22 February 2004.

Address for correspondence: Dr. Alonso Soto Tarazona. Mariano De Los Santos 161. San Isidro. Lima, Peru. Phone: 01 444-0664/01 4421464.E-mail: alosoto@hotmail.com

The Brazilian Journal of Infectious Diseases 2004;8(2):151-155 (C) 2004 by The Brazilian Journal of Infectious Diseases and Contexto Publishing. All rights reserved. accuracy of the results [5]. Therefore, in rural areas of our country with poor accessibility, which do not have these resources, many patients delay their treatment or receive their therapy based only on clinical criteria; this situation is not adequate [6], as this increases costs, exposes the patients to adverse reactions, and contributes to the development and dissemination of drug resistance [1,7-9].

For these reasons, rapid diagnostic strips have been developed. They are based on the capture of Plasmodium antigens. These strips are proving to be fast and reliable, and their utilization does not require specialized preparation. One of these methods is the OptiMAL, which is a dipstick that detects the lactate dehydrogenase enzyme of $P$. vivax and $P$. falciparum and can differentiate between these two parasites. This property is very important, because many areas of South America and Africa have both parasites coexisting in the same area. Although several studies 
have found a high sensitivity and specificity of the OptiMAL test for the diagnosis of P. falciparum [1013], there is little research about its validity for $P$. vivax, the most frequent parasite in South America [14]. Control of vivax malaria is important also, although it rarely results in severe malaria, while falciparum produces significant morbidity in our country.

Our objective was to determine the sensitivity and specificity of the rapid diagnostic test OptiMAL in comparison with microscopic evaluation of the thick smear for diagnosis of malaria due to $P$. vivax in an endemic area of high central jungle in Peru.

\section{Material and Methods}

\section{Patients}

The study was carried out in San Martin de Pangoa Hospital (HSMP), department of Junin, located in the central jungle area of Peru, between October and December 1998. This region is endemic for malaria, where more than $90 \%$ of cases are due to $P$. vivax, and there are a few cases of $P$. malarie [15].

The inclusion criteria were fever in the last 48 hours and age over 12 months. We excluded patients who had at least one of the following conditions:

- Having been treated with antimalaria drugs during the previous three weeks

- Presence of clinical signs of severe malaria

- Evidence of active infection other than malaria.

All patients signed an informed consent, which was previously reviewed and accepted by the Hospital's Ethics Committee. Demographic and clinical data were recorded, as well as a blood sample for white cell count, hemoglobin, thick blood film, thin blood film (for determining species) and to perform the OptiMAL test. An experienced microscopist read the thin and thick blood films. He was unaware of the other test results.

\section{Malaria diagnosis with microscopic examination}

The samples for thick and thin blood films were processed and read according to WHO standard procedures. The white blood cell count was determined manually, using a Neubauer's chamber. Afterwards, the parasitaemia was calculated as usual, relating the number of parasites to the number of leucocytes counted, and then calculating the number of parasites per microliter [16].

\section{Malaria diagnosis with OptiMAL}

OptiMAL is based on the detection of $P$. vivax and $P$. falciparum's lactate dehydrogenase enzyme, which, when present in the patient's blood, colors certain areas in the patient's test strip. An investigator, a technician newly trained in the performance of the test and blinded to the results of the microscopic evaluation, performed the Optimal test. The results were given in 10 minutes, but were not used to guide the patient's treatment.

\section{Analysis of the data}

To calculate the sensitivity, specificity, positive predictive value and negative predictive value of the Optimal test, our reference standard for diagnosis was the thick smear.

Chi Square $\left(X^{2}\right)$ and Fisher's exact tests were used to compare the sensitivity and specificity at several parasitemia levels. We used SPSS version 9.0 for Windows to record and to analyze data.

\section{Results}

Eighty patients were evaluated, 8 were excluded because of having taken chloroquine. 72 febrile patients were enrolled. $73 \%$ were males, the mean age was 25 years (minimum 4 years; maximum 82 years) and the mean duration of disease was 3.5 days. The most common symptoms besides fever were malaise (83\%) and headache $(55 \%)$.

Thirty-nine $(54 \%)$ of the patients had parasites in the thick blood film. The identification of species in the thin blood film only showed $P$. vivax. The median of the parasitemia load was 5,749 parasites/ul (minimum 27 - maximum 27,378). 
When comparing the performance of the OptiMAL test with the results of the thick smear, the OptiMAL's sensitivity for diagnosis of $P$. vivax was $92.3 \%$, the specificity $100 \%$, the positive predictive value $100 \%$ and the negative predictive value $91.6 \%$. (Table 1). The test's accuracy was $95.8 \%$. We also found that the OptiMAL's sensitivity decreased when parasitemia levels were low: the three patients who were positive for the thick smear and negative for the OptiMAL test had less than 600 parasites per microlitre (582, 227 and 79 parasites respectively) (Table 2 ). Sensitivity was significantly lower when patients had parasitemia levels of less than 1,000 parasites/ul ( $\mathrm{p}=0.049$, Fisher's Exact Test). One of the patients with a false negative result was positive for Plasmodium falciparum in the OptiMAL test, even though the thick smear only showed trophozoites consistent with infection by $P$. vivax, and the patient recovered with chloroquine. No false positives were found.

\section{Discussion}

We compared malaria diagnosis made by the rapid diagnostic test OptiMAL with traditional microscopic examination of the thick smear in an area where there is no $P$. falciparum malaria, with good results. We encountered a high prevalence of malaria $(53 \%)$ because the study was done during the malaria season. The OptiMAL's sensitivity and specificity were high for the diagnosis of $P$. vivax malaria, similar to other studies' findings, where the sensitivity varied between $62 \%$ and $98 \%$, and the specificity between $95 \%$ and $100 \%$ [1721]. The high positive and negative predictive values found in our study were also similar to those in other studies. We found that the OptiMAL sensitivity was associated with the level of parasitemia; the sensitivity was $100 \%$ when the parasitemia was higher than 1,000 parasites/ul, but decreased to $83.3 \%$ with lower parasitemia levels, and even to $33 \%$ with less than 100 parasites/ul. However,

Table 1. Results of OptiMAL and thick blood film exams of suspected malaria patients

\begin{tabular}{llll}
\hline & Positive thick blood film & Negative thick blood film & Total \\
\hline Positive OptiMAL & 36 & 00 & 36 \\
Negative OptiMAL & 03 & 33 & 36 \\
Total & $\mathbf{3 9}$ & $\mathbf{3 3}$ & $\mathbf{7 2}$ \\
\hline
\end{tabular}

Table 2. Sensitivity of OptiMAL related to parasitemia levels

\begin{tabular}{lll}
\hline Parasitemia (parasites/ul) & Number of patients & Sensitivity \\
\hline$\leq 500$ & 3 & $33 \%$ \\
$501-1,000$ & 6 & $83 \%$ \\
$1,001-5,000$ & 18 & $100 \%$ \\
$5,001-10,000$ & 3 & $100 \%$ \\
$>10,000$ & 9 & $100 \%$ \\
\hline
\end{tabular}


we had low numbers of patients in these subgroups. It is also worth remembering that even with a well-trained microscopist, it is difficult to diagnose malaria in patients with parasitemias of less than 250 parasites per microlitre with the thick smear, so this problem is not unique to OptiMAL. Even though overall OptiMAL seems to have less sensitivity than the thick smear, when PolymeraseChain Reaction (PCR) is used as gold standard, microscopic examination and OptiMAL havesimilar sensitivities, which are lower than that of the PCR exam [22].

This phenomenon has been described by Palmer et al. and in other studies, both for $P$. vivax and $P$. falciparum diagnosis, with $100 \%$ sensitivity for parasitemia higher than 1,000 parasites/ul, and $40 \%$ for values lower than 100 parasites/ul [23]. The explanation for this phenomenon could be that the quantity of $P$. vivax lactate dehydrogenase enzyme, the antigen detected by OptiMAL, is in direct proportion to the number of parasites in the blood [24]. This problem must be considered when this test is used in the field. Another limitation of the OptiMAL test is that it cannot identify patients with mixed infections of $P$. falciparum and $P$. vivax. The reason is that one of detected antigens is $P$. falciparum specific, but the other is not specific, because is a panmalaric antigen; therefore in mixed infections, the test will show a P. falciparum infection. Although the number of patients with mixed infection is low, it can be a therapeutic problem in endemic areas where more than one Plasmodium species coexists, and it can be as high as $8 \%-10 \%$ [6]. This was not our case, as Pangoa is an endemic area for $P$. vivax and $P$. malarie only. We did not encounter any cases of $P$. malarie; and we saw one case of $P$. falciparum diagnosed by OptiMAL, which in the thick smear was found to be $P$. vivax, although ideally, a PCR should have been made.

Nowadays, there are other rapid diagnostic tests whose utility in the field has been evaluated, such as ParaSight-F, ICT Pf and ICT Pf/Pv. ParaSight-F and ICT Pf are exclusive for $P$. falciparum (they detect the HRP-2 protein), and the others detect both species. All these rapid diagnosis tests have similar specificities and sensitivities, though they vary in their cost and devices. All of these, similarly to Optimal, have decreased sensitivity with decreases in parasitemia [25-31].
We found that the OptiMAL is a good alternative to thick smears for malaria diagnosis in areas endemic for $P$. vivax malaria. It has advantages over microscopic examination in speed of results (less than 20 minutes), ease of performance, as well as less need of laboratory facilities and health workers instruction. That is why it would be useful mainly in far-away places that do not have laboratories, as in the Central Peruvian Jungle, where the health providers are mainly nonprofessional personnel, who can however be adequately trained in the performance of rapid tests as has been previously proved [32]. But it is important to consider that it has diagnostic difficulties in patients with low parasitemia levels and it can not detect mixed infections, unlike microscopic examination.

However, the cost is one of the most important disadvantages for widespread use in developing countries. More studies are necessary to determine its cost-effectiveness, compared with microscopic examination, and to detect the differences between the different brands, and compared to other Rapid Malaria Diagnosis Devices.

\section{Acknowledgements}

We thank US NAMRID (Lima, Peru) for financial support and the Instituto de Medicina Tropical Alexander Von Humboldt. Lima, Peru, for providing facilities.

\section{References}

1. Aramburú J., Ramal C., Witzig R. Malaria Reemergence in the Peruvian Amazon Region. Emerging Infectious Diseases 1999;5(2).

2. Malaria Diagnosis. Memorandum from a WHO Meeting. Bulletin of the World Health Organization 1988,66:575-94.

3. A global strategy for malaria control. Geneva, World Health Organization, 1993.

4. National Policy for Antimalaric Medication. Health Ministry. Peru, 1999.

5. Implementation of the Global Malaria Control Strategy: Report of a WHO Study Group. World Health Organization. Geneva (WHO Technical Report Series No 839), 1993. 
6. Reporte de Manejo. Programa Nacional para el control de la malaria y otras enfermedades metaxénicas. Ministerio de Saludo. Lima, Peru, 1998.

7. Chauca H., Quintana J. Evaluación in vivo de la respuesta de Plasmodium falciparum a la cloroquina en foco carretera Yurimaguas-Tarapoto (Región Loreto). Revista Peruana de Epidemiología 1993;6:34-9.

8. Colan E., Quintana J., Ferreli R., et al. Malaria por Plasmodium falciparum en la Amazonía Peruana. Revista de Farmacología y Terapéutica 1993;3:11-6.

9. Navitsky R.C., Witzig R.S., Quintana Zurita J., et al. In vivo resistance of Plasmodium falciparum to pyrimethamine. Am J Trop Med Hyg 1997;57:229.

10. Jelinek T., Grobusch M.P., Schwenke S., et al. Sensitivity and Specificity of Dipstick tests for Rapid Diagnosis of Malaria in Nonimmune Travelers. Journal of Clinical Microbiology 1999:721-3.

11. Cooke A.H., Chiodini P., Doherty T., et al. Comparison of a parasite lactate dehydrogenase-based immunochromatographic antigen detection assay (OptiMAL) with microscopy for the detection of malaria parasites in human blood samples. Am J Trop Med Hyg 1999;60:173-6.

12. Quintana M., Piper R., Boling H.L., et al. Malaria diagnosis by dipstick assay in a Honduran population with coendemic Plasmodium falciparum and Plasmodium vivax. Am J Trop Med Hyg 1988;59:868-71.

13. Piper R.C., Lebras J., Wentworth L., et al. Immunocapture diagnostic assay for malaria utilizing Plasmodium lactate dehydrogenase (plDH). Am J Trop Med Hyg 1999;60:109-18.

14. Status of malaria programs in the Americas: XLIV Report. Washington: Pan American Health Organization; 1996 Sep. Document No: CD39/INF/2.

15. Health Situation in Peru. Basic Indicators. Statistics and Informatics Division. Health Minister. Peru, 1999

16. Bruce-Chwatt L.J. Parasite index in malaria. Trans R Soc Trop Med Hyg 1958;52:389.

17. Jelinek T., Grobusch M.P., Schwenke S., et al. Sensitivity and Specificity of Dipstick Tests for Rapid Diagnosis of Malaria in Nonimmune Travelers. Journal of Clinical Microbiology 1999:721-3.

18. Mackler M.T., Hinrichs D.J. Measurement of the lactate dehydrogenase activity of Plasmodium falciparum as an assessment of parasitemia. Am J Trop Med Hyg 1993;48:205-10.

19. Cooke A.H., Chiodini P., Doherty T., et al. Comparison of a parasite lactate dehydrogenase-based immunochromatographic antigen detection assay (OptiMAL) with microscopy for the detection of malaria parasites in human blood samples. Am J Trop Med Hyg 1999;60:173-6.
20. Quintana M., Piper R., Boling H.L., et al. Malaria diagnosis by dipstick assay in a Honduran population with coendemic Plasmodium falciparum and Plasmodium vivax. Am J Trop Med Hyg 1988;59:868-71.

21. Piper R.C., Lebras J., Wentworth L., et al. Immunocapture diagnostic assay for malaria utilizing Plasmodium lactate dehydrogenase (plDH). Am J Trop Med Hyg 1999;60:109-18.

22. Iqbal J., Sher A., Hira P.R., Al-Owaish R. Comparison of the OptiMAL test with PCR for diagnosis of malaria in immigrants. J Clin Microbiol 1999;37(11):3644-6.

23. Palmer C., Lindo J., Klaskala W., et al. Evaluation of the OptiMAL Test for Rapid Diagnosis of Plasmodium vivax ad Plasmodium falciparum Malaria. Journal of Clinical Microbiology 1998:203-6.

24. Makler M., Hinrichs D. Measurement of the lactate dehydrogenase activity of Plasmodium falciparum as an assessment of parasitemia. Am J Trop Med Hyg 1993;48(2):205-10.

25. Beadle C., Long G.W., Weiss W.R., et al. Diagnosis of malaria by detection of Plasmodium falciparum HRP-2 antigen with a rapid dipstick antigen-capture assay. Lancet 1994;343:564-8.

26. Mills C.D., Burgess D.C.H., Taylor H.J., Kain K.C. Evaluation of rapid and inexpensive dipstick assay for the diagnosis of Plasmodium falciparum malaria. Bulletin World Health Organization 1999;77:553-9.

27. Beadle C., Long G.W., Weiss W.R., et al. Diagnosis of malaria by detection of Plasmodium falciparum HRP-2 antigen with a rapid dipstick antigen-capture assay. Lancet 1994;343:564-8.

28. Di Perri G., Olliaro P., Nardi S., et al. The ParaSight-F rapid antigen capture assay for monitoring parasite clearence after drug treatment of Plasmodium falciparum malaria. Trans R Soc Trop Med Hyg 1997;91:403-5.

29. Schiff C.J., Premji Z., Minujas J.N. The rapid manual ParaSight-F test. A new diagnostic tool for Plasmodium falciparum infection. Trans R Soc Trop Med Hyg 1993;87:1-3.

30. World Health Organization. A rapid dipstick antigen capture assay for the diagnosis of falciparum malaria. WHO/MAL/95. 1072, 1995.

31. Tjitra E., Suprianto S., Dyer M., et al. Field evaluation of the ICT Malaria Pf/Pv Immunochromatographic Test for Detection of Plasmodium falciparum and Plasmodium vivax in Patients with a Presumptive Clinical Diagnosis of Malaria in Eastern Indonesia. Journal of Clinical Microbiology 1999:2412-7.

32. Ministerio de Salud. Evaluación del uso de una prueba rápida inmunocromatográfica por promotores de salud para el diagnóstico de malaria en áreas rurales de la Amazonía Peruana. Informe Técnico. Lima, Peru, 1999. 